\title{
Evaluation of Variation and Uncertainty in the Potential Yield of Soybeans in South Korea Using Multi-model Ensemble Climate Change Scenarios
}

\section{Chung $\mathbf{U}^{1 *}$, Kim $\mathrm{YU}^{2}$, Seo $\mathrm{BS}^{2}$ and Seo $\mathrm{MC}^{3}$}

${ }^{1}$ Climate Application Department, APEC Climate Center, Busan 48059, Republic of Korea

${ }^{2}$ Department of Plant Science, College of Agriculture and Life Science, Seoul National University, Seoul 08826, Republic of Korea

${ }^{3}$ Crop Production and Physiology Research Division, National Institute of Crop Science, Rural Development Administration, Jeonju 55365, Republic of Korea

\begin{abstract}
Recently, information provided by various Global Climate Models (GCMs) has been applied to various research fields. A Multi-model Ensemble (MME) approach, which assesses the impact of climate change on agricultural crop production using one or more climate datasets from GCMs, has been widely used. We estimated the changes in soybean potential yield at 16 sites using the climate change scenarios, and then predicted the relative change in predicted potential yield for each single GCM, producing an observation climate-based simulated potential yield. Lastly, we assessed the degree of uncertainty for changes in potential yield predicted from MME approach.

In the results, although there were differences in the values themselves, the Standard Deviations (SD) of predicted soybean potential yield for each individual GCM were not significantly different from the SD of observation climate-based simulated potential yield, and there were no correlations between the predicted soybean potential yield for each individual GCMs and observation climate-based simulated potential yield in most sites. The estimation error decreased as the number of participating GCMs in the MME increased, but it did not decrease to zero. The means, but not the variance, of the MME of potential yield of soybean was similar to that of the observation climatebased simulated potential yield. The relative changes for predicted soybean potential yield for individual GCMs values of the Representative Concentration Pathways 4.5 and 8.5 scenarios increased in the northern regions of South Korea, such as Chuncheon and Hongcheon. In contrast, differences between them were not significant in most southwestern regions.
\end{abstract}

Keywords: Climate change; CROPGRO-soybean; Multi-model Ensemble (MME); Rainfed; Uncertainty

\section{Introduction}

Korean farmers have recently been encouraged to grow field crops, particularly rainfed crops, by government policies aimed at promoting rice production and at achieving self-sufficiency in grain production. In South Korea, due to the climate, soybeans have been cultivated using a single cropping system in Chuncheon, Gangwon Province, and Yeoncheon, Gyeonggi-do Province. In the southern regions of South Korea, soybeans have been cultivated using a double cropping system, with soybeans planted after winter and spring crops such as winter barley, garlic, and onions. Recently, due to climate change, soybeans have been cultivated as summer crops, alongside potatoes and cabbages. However, concerns for the safe growth and yield of crops have been increasing due to the increased frequency of extreme weather events, such as heat waves and droughts. The optimum average air temperature for the reproductive growth period of the soybean is $29^{\circ} \mathrm{C}$, and at higher temperatures (e.g., $37^{\circ} \mathrm{C}$ ) the yield could potentially be greatly reduced [1]. The optimum average temperature for the reproductive growth stages of maize is $32^{\circ} \mathrm{C}[2,3]$; maize yields could be reduced by $5-13 \%$ even if temperatures increased by only $2^{\circ} \mathrm{C}$ during the growing season [4]. According to the Korean Meteorological Administration climate change report $[5,6]$, the daily average temperature of the Korean Peninsula will likely rise by between $2^{\circ} \mathrm{C}$ and $6^{\circ} \mathrm{C}$ respectively under the RCP (Representative Concentration Pathways) 4.5 and RCP8.5 scenarios by 2100 . In addition, the number of days with abnormally high temperatures, such as those caused by heat waves, is expected to increase to 13.1 days under the RCP4.5 scenario, and 30.2 days under the RCP8.5 scenario by 2100 , when compared to the present ( 7.3 days).

Responses to high temperature in the representative growth stages of wheat growth models such as CERES-Wheat, APSIM-N wheat, and
Wheat Grow have been improved, and many studies on the growth and yield responses of future climate scenarios that utilize these models have been published recently $[7,8]$. There have been numerous studies providing genetic information for various rice varieties, as well as on the effect of high temperature on rice production using rice growth models such as CERES-Rice and Oryza 2000 in Korea [9-12]. Research based on paddy growth models is relatively well structured in Korea, but there has been a lack of pure and applied research on field crops and on assessing the impacts of climate change. This is particularly the case for soybeans and maize, due to a lack of awareness regarding the importance of field crops, and because a database has not been established. Although there have been few studies that have used crop growth models, evaluated the growth and yield response of soybeans to the longer growing season and the later planting allowed for by the warming effects of climate change predicted the potential yield of soybeans under a future climate change scenarios for the Korean peninsula using CROPGRO-Soybean, a soybean growth model and suggested fluctuations in soybean production levels were likely assessed changes in the potential grain yield of soybeans due to changes in the plating date caused by higher temperatures during the growing season.

*Corresponding author: Chung U, Climate Application Department, APEC Climate Center, Busan 48059, Republic of Korea, Tel: +82-51-745-3971; E-mail: uchung@apcc21.org

Received July 17, 2017; Accepted July 25, 2017; Published August 01, 2017

Citation: Chung U, Kim YU, Seo BS, Seo MC (2017) Evaluation of Variation and Uncertainty in the Potential Yield of Soybeans in South Korea Using Multi-mode Ensemble Climate Change Scenarios. Agrotechnology 6: 158. doi: 10.4172/2168 9881.1000158

Copyright: ( 2017 Chung U, et al. This is an open-access article distributed unde the terms of the Creative Commons Attribution License, which permits unrestricted use, distribution, and reproduction in any medium, provided the original author and source are credited. 
While various future climate change scenarios have been used in climate change impact assessments in many applications, concerns regarding uncertainty in the future climate scenarios predicted by climate models have increased. Climate change data produced from the Global Climate Model (GCM) may only be suitable for analyzing changes in the average atmospheric characteristics at synoptic scales due to the low spatial resolutions ( 200 to $400 \mathrm{~km}$ ) and simplifications of physical processes. To overcome the limitations of the spatial resolution of the GCM, and to produce more detailed climate information, dynamic downscaling methods uses Regional Climate Models (RCM) that can take into account the physical processes of a particular area have been developed [13-15]. As another way to resolve this uncertainty, a few methods have been developed. One such method is a bias correction method that corrects for the systematic bias between GCMs by comparing past climate change scenarios predicted by GCMs with observational data from the same period to evaluate whether GCM that have already been developed can reproduce past climates. Models that apply spatial downscaling to make predictions at the national scale are currently being developed, using the statistical multi-criteria selection method of GCM or RCM data $[16,17]$. Another method that is used in climate science to reduce uncertainty and produce reliable future climate change data is the multi-model ensemble (MME) approach, a method that combines climate information from more than one GCM [18-23]. MME simulation, that uses more than one crop growth model, is also currently applied to the evaluation of crop productivity in agriculture research [24-26].

The purpose of this study is therefore to examine changes in yield and response of soybeans in crop growth models where the various future climate scenarios have been downscaled to reflect the topography of South Korea. The study will also determine whether an MME approach can contribute to the assessment of the impacts of climatic uncertainty on the potential grain yields of soybeans under various future climate change scenarios.

\section{Materials and Methods}

\section{Crop model: CROPGRO-soybean}

This study used DSSAT (Decision Support System for Agrotechnology Transfer), a software package that can simulate the growth of various crops by use of the same input/output files, and is one of the most widely used crop growth models world-wide [24,27]. Beans such as peanuts and soybeans are simulated by the DSSAT CROPGRO growth model. CROPGRO can simulate the growth of soybeans and the balance of carbon and nitrogen within agricultural systems (such as uptake, fixation, and formation by the soil system) by inputting daily weather conditions to the model [28-30].

\section{Observation and genetic parameters}

The National Institute of Crop Science (NICS) of Korea has regional offices and experimental fields across South Korea, where studies on topics such as crop adaptation are conducted. Chuncheon, Suwom, Jeonju, Miryang, Jinju, and Daegu are representative experimental fields that have previously been used as test sites for studies on crop adaptation (Figure 1). Among the Korean soybean cultivars grown, Taegwang is the main cultivar in the southern part of Korea [31,32] have calibrated and validated the genetic parameters of Taegwang, based on the experiment data of Yeoncheon and Suwon collected in Gyeonggi-do and in Jinju in the southern region of South Korea from 1992 to 2000 (data not show). In this study, the genetic parameters, which were calibrated using the CROPGRO-Soybean by Kim et al.
[32] were tested at six sites (Daegu, Jinju, Miryang, Jeonju, Suwon, and Chuncheon) for 11 years from 2003 to 2013. Weather data from the Automated Surface Observing System (ASOS) run by the Korean Meteorological Administration (KMA) were used because, as detailed earlier, we examined the growth and yield responses of soybeans using ASOS weather data in the crop model, and explored changes in potential grain yield based on future climate scenarios from Global Climate Models (GCMs) that had been downscaled using topographical information from ASOS. To evaluate genetic parameters, the weather data for 2003 to 2013 were collected from 6 ASOS weather stations near where the experimental fields were located. Additionally, the weather data of 10 ASOS weather stations for the same period (2003-2013) were collected and applied to the model (Figure 1 and Table 1).

\section{Soil data}

All soil information required for DSSAT soil input parameters was taken from the precision digital soil map produced by the National Institute of Agricultural Science (NAS). This map provides detailed information on the physical and chemical properties of the soil texture. Information from DSSAT soil profiles regarding the locations of the 16 ASOS weather stations was extracted from the digital map for use in this study.

\section{Climate scenario data}

Past and future climate change scenarios of global climate models: GCMs included in CMIP5 (Coupled Model Intercomparison Project) were selected for this study. In particular, we collected data from eight GCMs and one regional climate model (RCM) from the Representative Concentration Pathways (RCP) scenarios that were able to provide the minimum input meteorological variables (e.g., daily maximum and minimum temperature, precipitation, and solar radiation) required to run the crop model from 1976 to 2100 (Table 2).

Downscaled climate change scenarios: Spatial downscaling of the climate models to suit the sites was required since the data collected from the nine climate change scenarios did not reflect the geographical features and regional characteristics of the selected weather stations. Therefore, the data from the relevant climate scenarios were downscaled using the nonparametric quantile mapping methods described by Gudmundsson et al. [16] that can simultaneously apply spatial downscaling and bias correction [23].

\section{Application and analysis}

Simulation options used for the crop model: In South Korea, soybeans are planted in the middle of June for double cropping systems in the southern region, or at the end of May for single cropping systems in the central and northern regions. The planting dates for Chuncheon, Hongcheon, and Suwon, which are located in the middle and northern regions of the Korean peninsula, were May 25. The planting date for Cheongju, Daejeon, Gunsan, Jeonju, Buan, Jeongeup, Daegu, Jinju, Yeongdeok, Miryang, and Jangheung in the southern regions was June 10 (Table 1). Initial fertilization was provided in the form of N-P-K, with an input of $40 \mathrm{~kg} / \mathrm{ha} \mathrm{N}, 30 \mathrm{~kg} / \mathrm{ha} \mathrm{P}$ and $30 \mathrm{~kg} / \mathrm{ha} \mathrm{K}$. May 25 and June 10 were respectively applied as an estimate of future planting dates according to the location of the sites, and CROPGRO-Soybean was run with an assumption of no abiotic stress (e.g., stress due to lack of water or nitrogen) being present. Two methods are available for setting up projected $\mathrm{CO}_{2}$ levels for future climate change scenarios. One method is to modify the CO2045. WDA file included with DSSAT, and the other method is to set $\mathrm{CO}_{2}$ environment parameters manually in the DSSAT experiment file (fileX). For this study, the $\mathrm{CO}_{2}$ environment for RCP 4.5 and RCP 8.5 was set manually in the experiment fileX. 


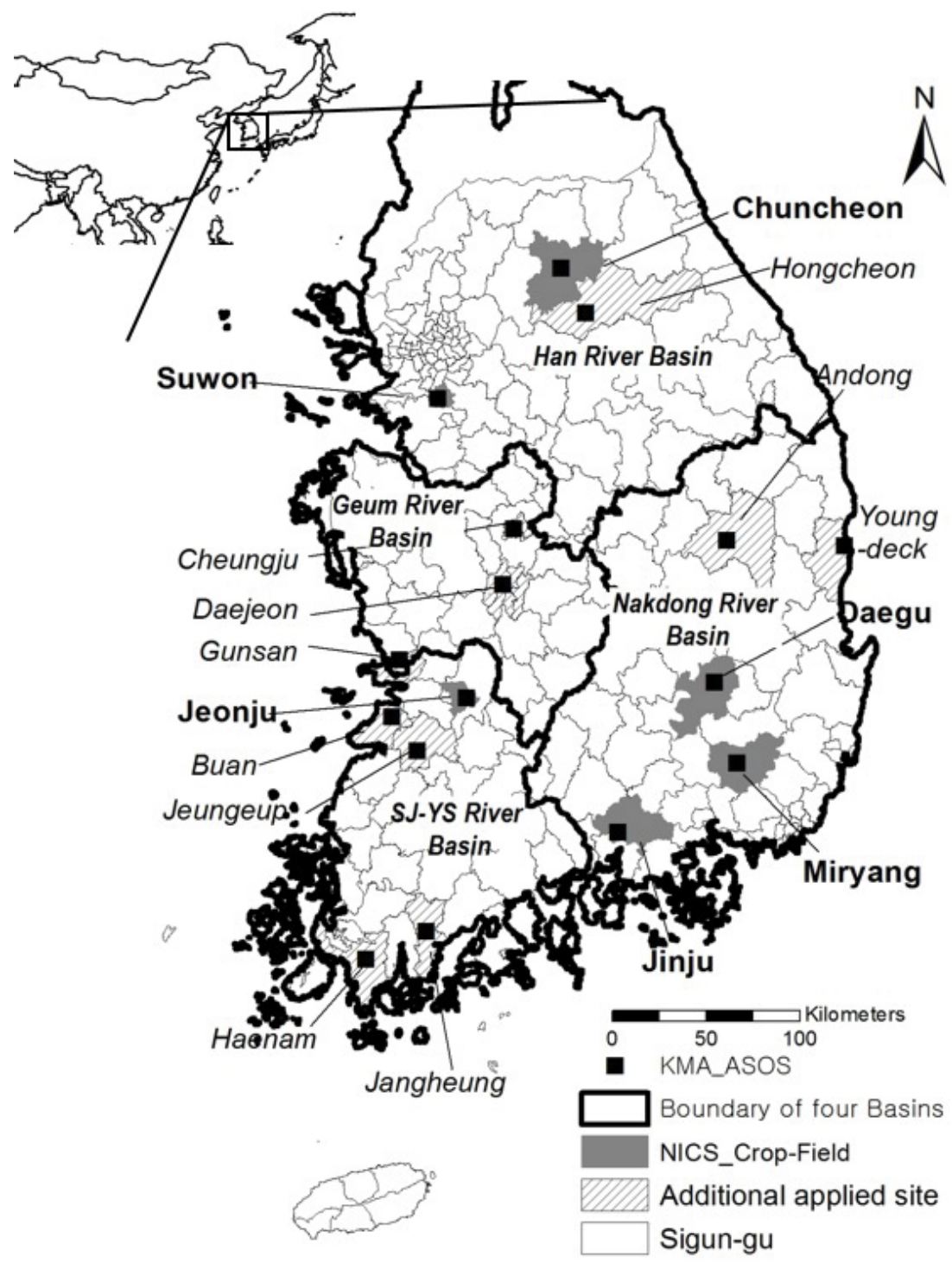

Figure 1: Geographical locations of the six sites (bold letters and gray polygons) of NICS (National Institute of Crop Science) at which the genetic parameters of "Taegwang" were calibrated and validated. In addition, the locations of 10 sites (italic letters and hash polygons) for CROPGRO-Soybean simulation are shown. Bold boundaries delineate the four main basins (Han-River, Nakdong-River, Geum-River, and Seum Jin-Young San (SJ-YS)-River) in South Korea.

Statistical analysis: The simulation period of CROPGRO-Soybean for past climate change scenarios was from 1976 to 2005. This period was chosen because the future climate change scenarios used by CMIP5 in this study had been forecast since 2006, and we then selected the 30 year period from 1976 to 2005 of past climate change scenarios for this analysis. For projections from 2006 to 2100, the near future period used in this study was set from 2021 to 2050. The coefficient of determination (R2) and root mean squared error (RMSE) were calculated to validate the impact on the potential yields of the genetic parameters of Taegwang.

The potential yield of Taegwang estimated from the observed weather data for the past period (1976-2005) was used as the observation climate-based simulated potential yield (OBS-SIM-PYD) for this analysis. The potential yields of Taegwang predicted by the past and future climate change scenarios of eight individual GCMs and one RCM were also used as the simulated potential yields for individual
GCMs (individual-SIM-PYDs). The interquartile range (IQR) of individual-SIM-PYD for the past 30 years from 1976 to 2005 was calculated. The IQR can be obtained by subtracting the first quartile from the $3^{\text {rd }}$ quartile.

The multi-model ensemble (MME) approach was constructed from the averages of the individual-SIM-PYDs. First, the average of two individual-SIM-PYDs that had high correlation with OBS-SIMPYD was named as the high correlation MME averaged potential yield (MME2C-PYD). Second, the high IQR MME averaged potential yield (MME2H-PYD) was calculated by averaging two individual-SIM-PYDs that had the most similar IQR. Third, the MME4 averaged potential yield (MME4-PYD) was calculated by averaging two individual-SIM-PYDs with high correlation and two individual-SIM-PYDs with high IQR values. Lastly, the average of all nine individual-SIM-PYDs produced the MME9 averaged potential yield (MME9-PYD). 


\begin{tabular}{|c|c|c|c|}
\hline Station ID & Site & Planting day & Basin \\
\hline ID131 & Cheungju & 10-Jun & \multirow{6}{*}{ Geum-River Basin } \\
\hline ID133 & Daejeon & 10-Jun & \\
\hline ID140 & Gunsan & 10-Jun & \\
\hline ID146 & Jeonju & 10-Jun & \\
\hline ID159 & Buan & 10-Jun & \\
\hline ID245 & Jeoungeup & 10-Jun & \\
\hline ID143 & Daegu & 10-Jun & \multirow{5}{*}{ Nakdong-River Basin } \\
\hline ID192 & Jinju & 10-Jun & \\
\hline ID277 & Youngdeck & 10-Jun & \\
\hline ID288 & Miryang & 10-Jun & \\
\hline ID136 & Andong & 10-Jun & \\
\hline ID260 & Jangheung & 10-Jun & \multirow{2}{*}{ SJ-YS-River Basin } \\
\hline ID261 & Haenam & 10-Jun & \\
\hline ID101 & Chuncheon & 25-May & \multirow{3}{*}{ Han-River Basin } \\
\hline ID119 & Suwon & 25-May & \\
\hline ID212 & Hongcheon & 25-May & \\
\hline
\end{tabular}

Table 1: Information about basins in which the 16 sites were located and the planting time at each site. Refer to Figure 1 for geographical location of basins.

\begin{tabular}{|c|c|c|c|}
\hline Model & Origin & Country & Resolution \\
\hline KMA-12 km & rea Meteorological Adm & & $12.5 \times$ \\
\hline CanESM2 & $\begin{array}{r}\text { Canadian Centr } \\
\text { anc }\end{array}$ & Canada & $2.8^{\circ}$ \\
\hline GFDL & \multirow{2}{*}{$\begin{array}{l}\text { NOAA/GFDL (Geophysical Fluid } \\
\text { Dynamic Laboratory) }\end{array}$} & \multirow[b]{2}{*}{ USA } & \multirow{2}{*}{$2.5^{\circ} \times 2.0^{\circ}$} \\
\hline GFDL-ESM2M & & & \\
\hline HadGEN & Meteorological Office Hadley Center & & \\
\hline inmcm4 & Institute for Numerical Ma & $\mathrm{a}$ & $5^{\circ}$ \\
\hline IPSL-CM5A-LR & Institute Pierre Simon Laplac & & \\
\hline $\begin{array}{l}\text { MIROC-ES } \\
\text { CHEM }\end{array}$ & $\begin{array}{c}\text { Atmosphere and Ocean Research } \\
\text { Institute, National Institute for } \\
\text { Environmental Studies, and Japan } \\
\text { Agency for Marine-Earth Science and } \\
\text { Technology }\end{array}$ & Japan & $2.8^{\circ} \times 2.8^{\circ}$ \\
\hline
\end{tabular}

Table 2: List of 8 individual Global Climate Models (GCMs) and one individual Regional Climate Model (RCM) used in this study.

The relative change of the predicted potential yields of each individual climate model (individual-SIM-PYD) for the observation climate-based simulated potential yield (OBS-SIM-PYD) was calculated using Equation 1.

Relative Change $=$

$\underline{(M M E 2 C \text { of PYD or MME2H of PYD or MME9 of PYD })-(O B S-S I M-P Y D)} \times 100$ $(O B S-S I M-P Y D)$

MME2C of PYD, MME2H of PYD, or MME9 of PYD are the average ensemble of individual-SIM-PYDs according to the average ensemble method (i.e., type of GCMs and the number of participants), and OBS$S I M-P Y D$ is the potential yield that was estimated from the observed weather data.

Therefore, we first analyzed the changes in potential yield of 16 sites from the climate change scenarios, and then calculated the relative change in the predicted potential yield of each single GCM for the observation climate-based simulated potential yield, and lastly assessed the degree of uncertainty regarding changes in potential yield predicted using the MME approach.

\section{Results}

\section{Evaluation of genetic parameters}

We used the CROPGRO-Soybean model to simulate soybean cultivation at six National Institute of Crop Science (NICS) sites during 2003 to 2013 to estimate the anthesis day and the potential yield of Taegwang, and to validate the genetic parameters described by Kim et al. [32]. The coefficient of determination $\left(R^{2}\right)$ of the potential yield predicted by the observation were 0.82 in Jinju, $0.43,0.41,0.38$, and 0.37 for Daegu, Jeonju, Suwon, and Chuncheon, respectively, and 0.37 for Miryang. The spatial average $\mathrm{R}^{2}$ was 0.40 in all six sites, and the predictability of potential yield was determined to not be high (Figure 2 ). For anthesis day prediction, the highest $R^{2}$ was 0.88 in Miryang, where the $\mathrm{R}^{2}$ of the potential yield was not useful. The $\mathrm{R}^{2}$ of the predicted anthesis days in Jinju and Daegu were 0.87 and 0.58 , respectively, and $0.29,0.39$, and 0.45 for Jeonju, Suwon, and Chuncheon, respectively. The spatial average $\mathrm{R}^{2}$ of the predicted anthesis days in six sites was 0.58 , which was better than the predictability of the potential yield.

\section{Potential yield of soybeans under different climate change scenarios}

Changes of potential yield of soybeans in individual past climate change data: Figure 3 shows the Standard Deviations (SD) and the correlation coefficients of the predicted potential yield for the eight individual Global Climate Models (GCMs) and one Regional Climate Model (RCM) in all six sites during 1976 to 2005. Black circles represent the SDs and correlation coefficients of the observation climate-based simulated potential yield (OBS-SIM-PYD) at all six sites, and circles of red, yellow, orange, pink, blue, green, brown, sky blue, magenta color indicated the SDs and correlation coefficients of the predicted potential yield of each individual climate model (Individual-SIM-PYDs). Each single climate model was indicated in the order CanESM2, MIROCESM-CHEM, GFDL-ESM2G, HadGEM2-CC, INMCM4, KMA125 $\mathrm{km}$, IPSL-CM5A-LR, GFDL-ESM2M, and MIROC-ESM. White circles show the SD and correlation coefficient of the nine Multimodel Ensemble (MME) averaged potential yield (MME9-PYD) that was produced from the averaged potential yields of eight individual GCMs and one RCM. Although there were differences in the values themselves, the SD of individual-SIM-PYDs did not deviate from the SD of OBS-SIM-PYD. There were no correlations between individualSIM-PYDs and OBS-SIM-PYD for most sites. However, especially in Miryang and Jinju, the SD of individual-SIM-PYDs for KMA125 km of RCM were large but showed a trend towards increasing correlation with OBS-SIM-PYD.

The change in potential yield of soybeans predicted by the multi-model ensemble: If the number of models included in an MME increases, the error does not decrease to zero $[23,25]$. The root mean square errors (RMSEs) were calculated according to the averaged MME ensemble for the combination of type and number of GCMs (Figure 4). In 16 sites, the average of RMSE of individual-SIM-PYD was $508 \mathrm{~kg} / \mathrm{ha}$, the averaged RMSE decreased as the number of GCMs increased from 2 to 3 . The decline in the averaged RMSE slowed at six GCMs, and stopped at eight GCMs; the averaged RMSE was not significantly reduced even at 7, 8, or 9 GCMs. The estimation error in the individual-SIM-PYDs reduced as the number of models included in the MME increased. The way in which the potential yield averaged by MME represented variations in the observation climate-based predicted potential yields (OBS-SIM-PYD) is also important. Variation (e.g., IQR) $s$ in the individual-SIM-PYDs during the past period (19762005) averaged by MME depending on the individual-SIM-PYDs of each single GCM included in the average were compared (Figure 5). Although the variation in individual-SIM-PYDs averaged by MME varied depending on the type and number of included climate models, generally the variance of MME2C-PYD and MME2H-PYD showed 

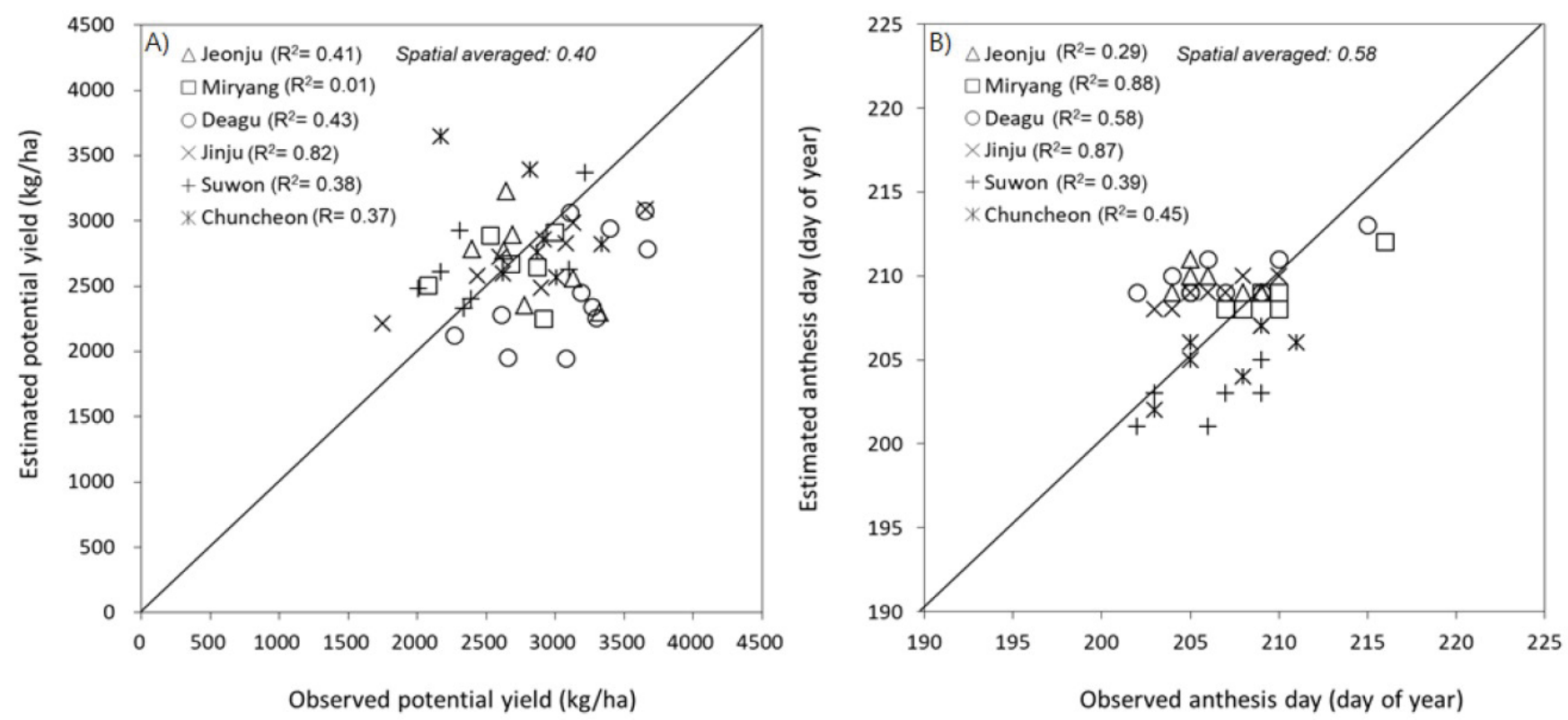

Figure 2: Comparison of predictability of the potential yield (A) and flowering time (B) based on genetic parameters of "Taegwang", from 2003 to 2013 at the 6 sites (Jinju, Suwon, Chuncheon, Daegu, Miryang, and Jeonju).

better reproducibility of the variance in the OBS-SIM-PYD than MME4-PYD or MME9-PYD. In order words, the mean of MME4-PYD or MME9-PYD seemed to be similar to the mean of OBS-SIM-PYD, but they were too averaged to have a small fluctuation range (i.e., IQR) and they could not effectively reproduce the variation of OBS-SIMPYD.

\section{The relative change in the predicted potential yield of soybeans under future climate change scenarios}

The relative change of the predicted potential yield of soybeans under the future climate scenarios of the Representative Concentration Pathways (RCP) 4.5 and 8.5, respectively, for 2021-2050 was calculated using Equation 1, based on the individual-SIM-PYDs of past climates from the GCMs. In 16 sites from 2021 to 2050, the averaged relative change in individual-SIM-PYDs for future climate change scenarios for eight GCMs and one RCM under RCP4.5 and RCP8.5 was: $-12.6 \% /-16.3 \%$ in Daegu, $-8.6 \% /-12.2 \%$ in Miryang, $-8.5 \% /-10.4 \%$ in Jeonju, $-8.9 \% /-10.6 \%$ in Jinju, $-2.9 \% /-4.7 \%$ in Suwon, $1.2 \% /-1.2 \%$ in Chuncheon, $-0.6 \% /-2.8 \%$ in Cheongju, $-4.5 \% /-6.4 \%$ in Daejeon, $-8.7 \% /-$ $11.5 \%$ in Gunsan, $-9.0 \% /-10.0 \%$ in Buan, $-11.1 \% /-11.2 \%$ in Jeungeup, $-11.8 \% /-13.7 \%$ in Jangheung, $-11.6 \% /-12.7 \%$ in Haenam, $5.7 \% / 4.1 \%$ in Hongcheon, $-3.2 \% /-3.8 \%$ in Andong, and -2.9\%/-4.8\% in Youngdeck (Figure 6). In particular, the relative changes in individual-SIM-PYDs of other regions, with the exception of Hongcheon and Chuncheon (which are located in the middle north of South Korea), decreased during the near future period. In Hongcheon and Chuncheon, the relative changes in the individual-SIM-PYDs increased, and showed a positive impact on future temperature increases.

\section{Discussion}

\section{The predictability of genetic parameters in Taegwang}

The prediction for the anthesis day and potential yield in Jinju during 2003-2013 proved reliable since the Taegwang genetic parameters of Kim et al. [32] were constructed using data from Jinju.
Given that soybeans are sensitive to day length, the predictions of the anthesis day for Miryang and Daegu were accurate, as these two sites are geographically close to Jinju and hence have similar day lengths. In contrast with the accurate prediction of the anthesis day in Miryang, the prediction of the potential yield was not accurate. We were not able to determine whether the prediction of the potential yield was not accurate due to insufficient observed yield data from the Mirayng site. However, as mentioned in the Introduction, it could be suggested that, due to the lack of existing case studies of crop model in South Korea, not enough genetic parameters or high quality observation data are available for the calibration and validation of input parameters for crop modeling [33-36].

\section{The predictability of the potential yield of soybeans with climate change}

The reproducibility of the potential yield of soybeans under past climate change scenarios: As shown Figure 3, during the past period (1976-2005), the predicted potential yield for individual global climate models (GCMs) (individual-SIM-PYDs) did not reproduce the observation climate-based simulated potential yield (OBS-SIM-PYD) since the correlation between the individual-SIM-PYDs and OBS-SIMPYD was low. This result was similar to the observations [37], who found that the cherry flowering day predicted based on the past climate change scenarios from individual GCMs did not match the observed cherry flowering day. However, the correlation between the individualSIM-PYDs of regional climate model (RCM) and the OBS-SIM-PYD is higher than that of the individual-SIM-PYDs of GCMs. This would be expected, because the RCM was dynamically downscaled from the GCM using regional topogeographical factors.

Even if the past climate changes modelled by GCMs were appropriately downscaled and reproduced the observations made during the past period, and this appropriately downscaled climate information was input into the crop model, the crop model may still show different results to what were actually observed. This is because 
Citation: Chung U, Kim YU, Seo BS, Seo MC (2017) Evaluation of Variation and Uncertainty in the Potential Yield of Soybeans in South Korea Using Multi-model Ensemble Climate Change Scenarios. Agrotechnology 6: 158. doi: 10.4172/2168-9881.1000158

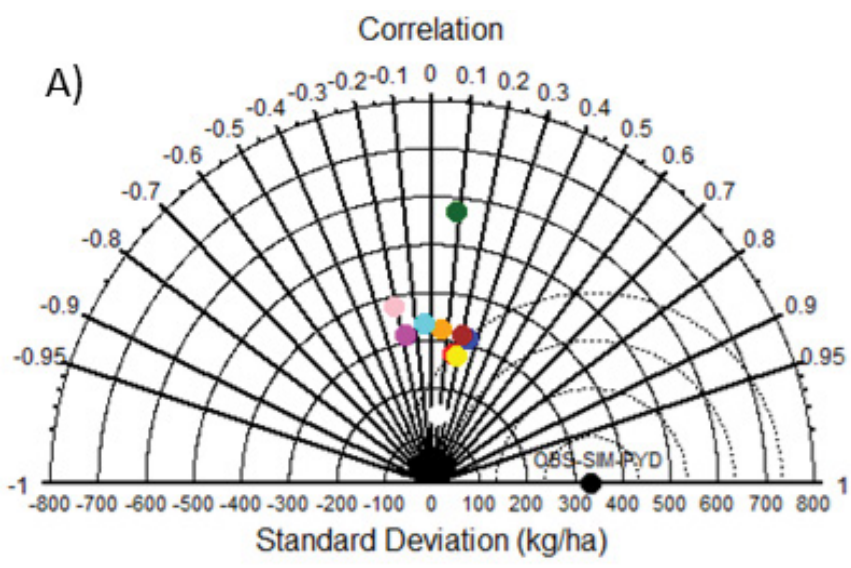

Correlation

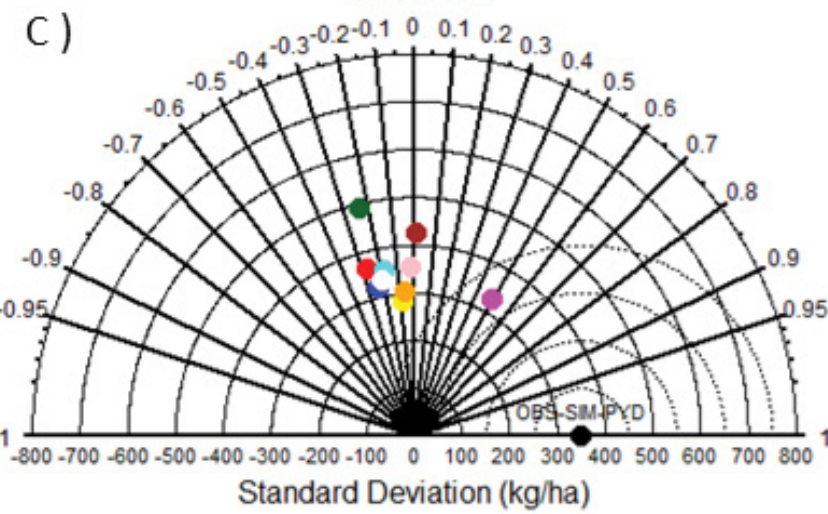

Correlation

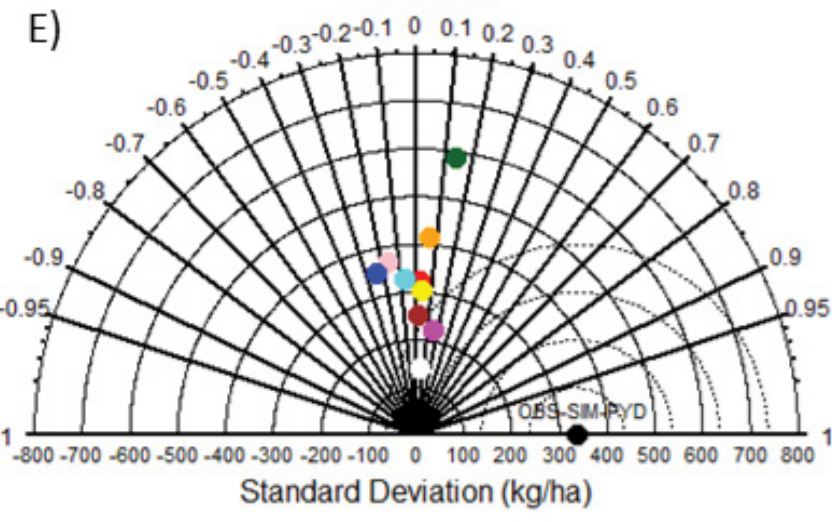

Correlation

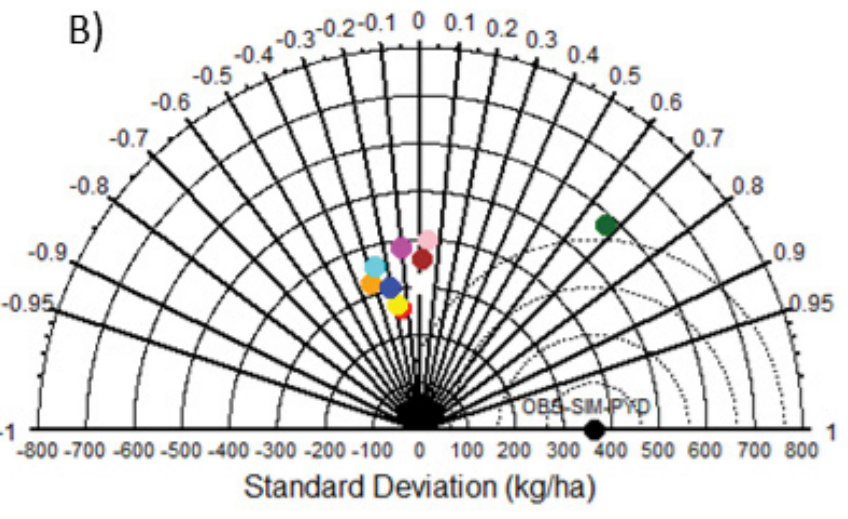

Correlation

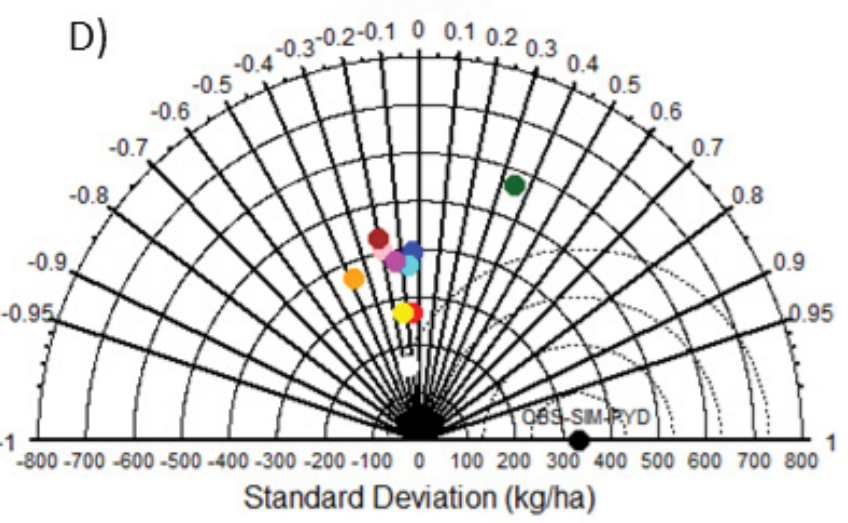

Correlation

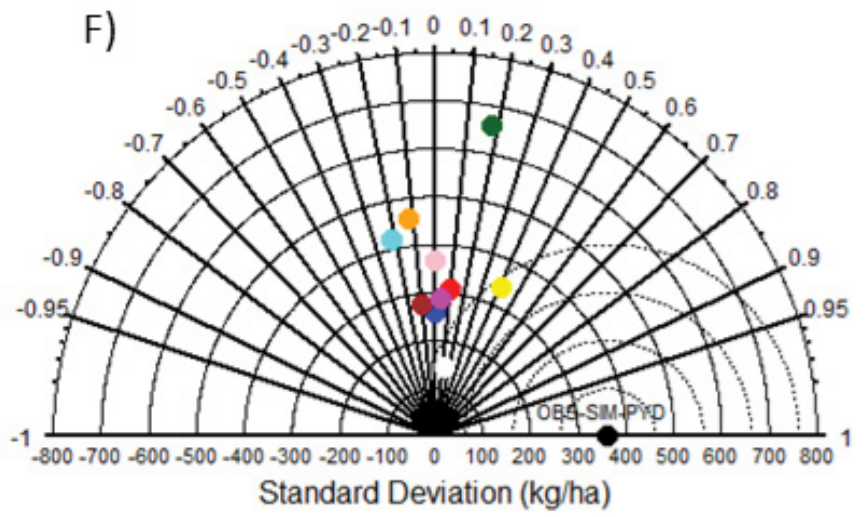

$\begin{array}{llll}\text { CanESM2 } & \bullet & \text { KMA125km } \\ \text { MIROC-ESM-CHEM } & \text { IPSL-CM5A-LR } \\ \text { GFDL-ESM2G } & \bullet & \text { GFDL-ESM2M } \\ \text { HadGEM2 } & \bullet & \text { MIROC-ESM } \\ \text { INMCM4 } & \circ & \text { MME 9 } \\ & & \bullet & \text { OBS-SIM-PYD }\end{array}$

Figure 3: The correlation coefficients versus the standard deviations (SD) for the potential yields (SIM-PYDs) of eight global climate models and one regional climate model (RCM), simulated from CROPGRO-Soybean at six stations (A: Daegu, B: Miryang, C: Jeonju, D: Jinju, E: Suwon, F: Chuncheon). The colored dots indicate the correlation coefficients and the SDs of the 8 individual global climate models (GCMs). The solid black circle represents the correlation coefficient and the SD of the observed predicted potential yield (OBS-SIM PYD) between 1976 and 2005. The solid white circle expresses the correlation coefficient and the SD of the mean averaged potential yield (MME9) simulated from the eight GCMs and one RCM during the same period. 


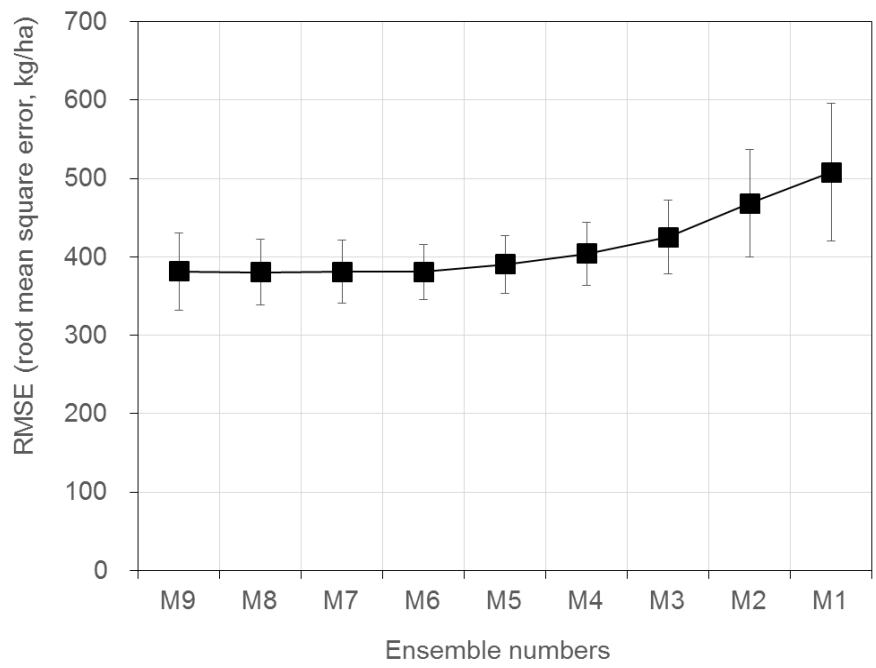

Figure 4: The Root Mean Square Error (RMSE) versus the ensemble type (numbered M1-M8) for each individual climate models.

the crop model is not a simple model (e.g., growing degree day) that predicts plant responses to temperature. It is therefore necessary to analyze in more detail whether the downscaled climate data from GCMs during the major crop growth periods reproduced the observed climate accurately enough, and to evaluate the plant responses in the crop model.

The uncertainty of the potential yield of soybeans by multimodel ensemble: According to Martre et al. [25], as the number of GCMs participating in the Multi-model Ensemble (MME) increased, the Root Mean Squared Error (RMSE) decreased, but the RMSE converged at a certain number instead of continuously decreasing. For the assessment of the agricultural climate index on the future climate change on the Korean peninsula, the RMSE decreased when the number of participation of GCMs reached the maximum, but converged at a certain number rather than continuously increasing [23]. As shown in Figure 4, the estimation error (e.g., RMSE) decreased as the number of GMCs included in the MME increased, but it did not decrease to zero. It is necessary to provide information on the type and number of individual GCMs that can reduce the estimation error by as much as possible, rather than including arbitrarily large numbers of GCMs in the MME.

In addition, the mean of the MME4 averaged potential yields (MME4-PYD) or the MME9 averaged potential yields (MME9PYD) were similar to the OBS-SIM-PYD, but the range of variations (e.g., interquartile range) of the predicted potential yield was small and showed the typical features of the statistical method, so that the potential yield could not be predicted for any given climate change scenario, such as high temperature events. In a study by Chung et al. [37], which was conducted from 1976 to 2005, the average cherry flowering day predicted by an MME were similar to the observed cherry blossoming day, however, the yearly variations in the cherry flowering day that were caused by annual weather differences were not reproduced. The average predicted potential yield, which is the last information available from the climate change and crop model, is relatively similar to the observed yield; the predicted potential yield was not reproducible due to annual variations in the weather. It could be more important to provide information on the individual GCMs that are able to reproduce changes in the predicted potential yield of soybeans under conditions of climate change in South Korea, rather than to involve more, or more or many types of individual GCMs, in the MME.

\section{The relative change in predicted potential yield for future climate change scenarios}

In most southern regions, the future potential soybean yields will be lower than at present, since in MME the relative change of the potential yields of soybean was expected to decrease in the near future under RCP4.5 and RCP8.5 scenarios at the most sites, with the exception of only two sites among the 16 sites studied. However, the relative change in the potential yield at Chuncheon was increased by $4 \%$ for the RCP 4.5 scenario and was decreased to $-1 \%$ for the RCP 8.5 scenario. In Hongcheon, the relative change in the potential yield was increased to $6 \%$ for the RCP4.5 scenario and $4 \%$ for the RCP8.5 scenario, respectively. There is an increased probability that the potential yield of soybeans in Gangwon and the north of Gyeonggi-do in South Korea may itself increase rather than decrease.

\section{Conclusion}

In general, a change in the potential yield of a crop will naturally occur in response to local differences. In the northern regions of South Korea, such as Chuncheon and Hongcheon, the temperature increase had a positive effect, and the predicted potential yield of soybeans was increased by future climate change in those areas. The relative changes in predicted potential grain yields under RCP4.5 and RCP8.5 scenarios increased, although the difference between them was not significant in the most southwestern regions. If no experimental data available that can be validated under conditions such as a temperature gradient, such models will remain merely theoretical and without practical applicability. Lately, studies have been actively conducted to reproduce the future climate conditions in South Korea and to directly estimate the growth responses of crops. Improved results for crop modelling will be produced if experimental studies and crop modelling are carried out together.

It could not be concluded that the Multi-model Ensemble (MME) approach reduced the estimation error, but it did reduce the uncertainty of the predicted potential yield of soybeans under future 

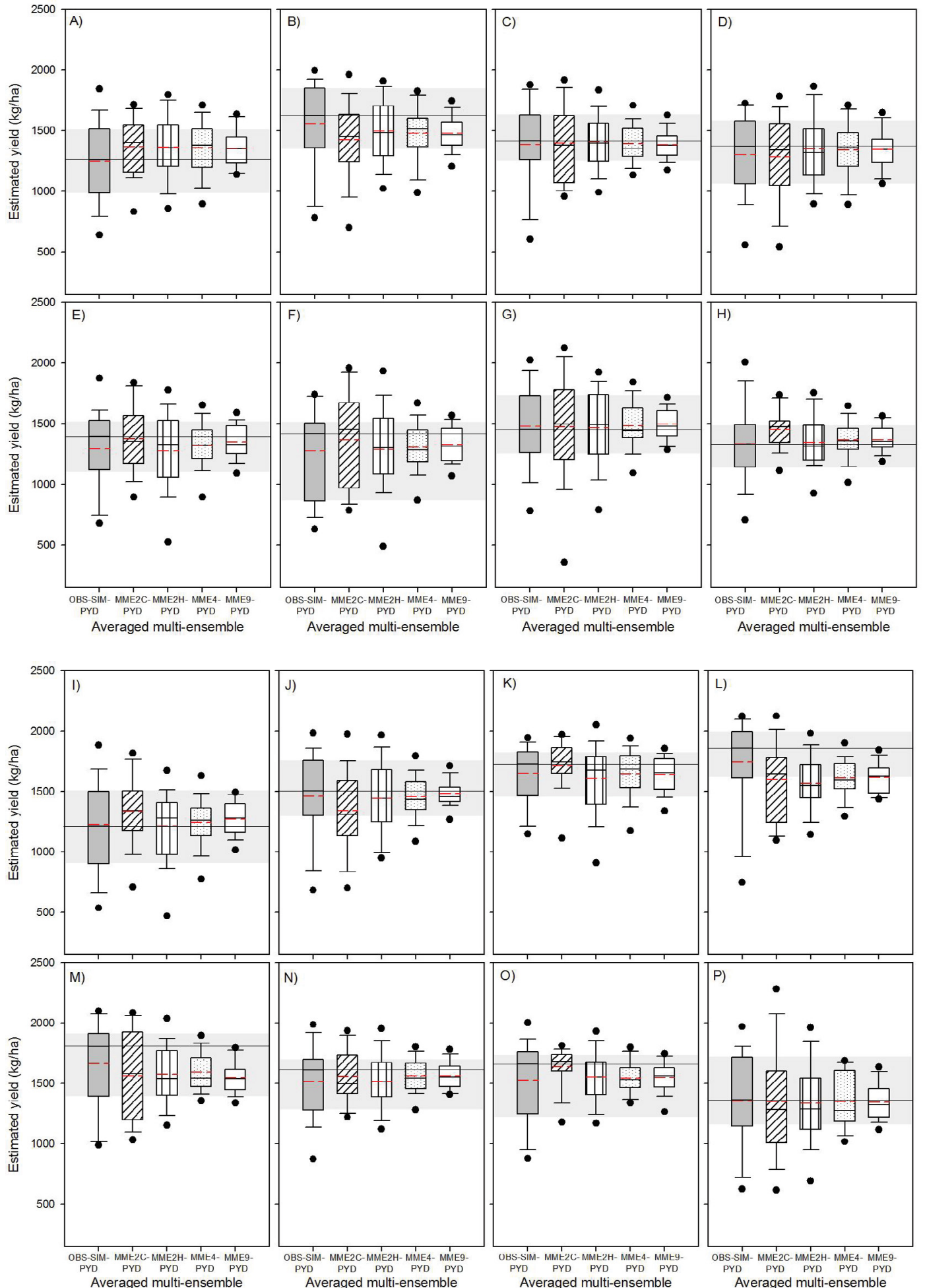

Figure 5: Comparison of the mean potential yields averaged by applying four ensemble methods to each of 16 sites (A: Daegu B: Miryang, C: Jeonju, D: Jinju, E: Suwon, F: Chuncheon, G: Hongcheon, H: Andong, I: Cheungju, J: Daejeon, K: Gunsan, L: Buan, M: Jeungeup, N: Jangheung, O: Haenam, P: Youngdeck). OBS-SIM-PYD estimated the potential yield from CROPGRO-Soybean for the observed weather from 1976 to 2005. MME2C-PYD estimated the mean potential yield averaged from the individual SIM-PYDs of two GCMs with the highest correlation to OBS-SIM-PYD among the individual SIM-PYD of nine GCMs. MME2HPYD estimated the mean potential yield averaged from the individual SIM-PYDs of two GCMs with the highest correlation to the interquartile range (IQR) of OBSSIM-PYD. MME4-PYD estimated the mean potential yield averaged from four individual SIM-PYDs, including two individual SIM-PYDs of MME2C-PYD and two individual SIM-PYDs of MME2H-PYD. MME9 represents the mean potential yield averaged from the individual SIM-PYDs of all nine GCMs. Box-and-whisker plots represent means and SDs, red lines and black dots represent medians and ranges. 


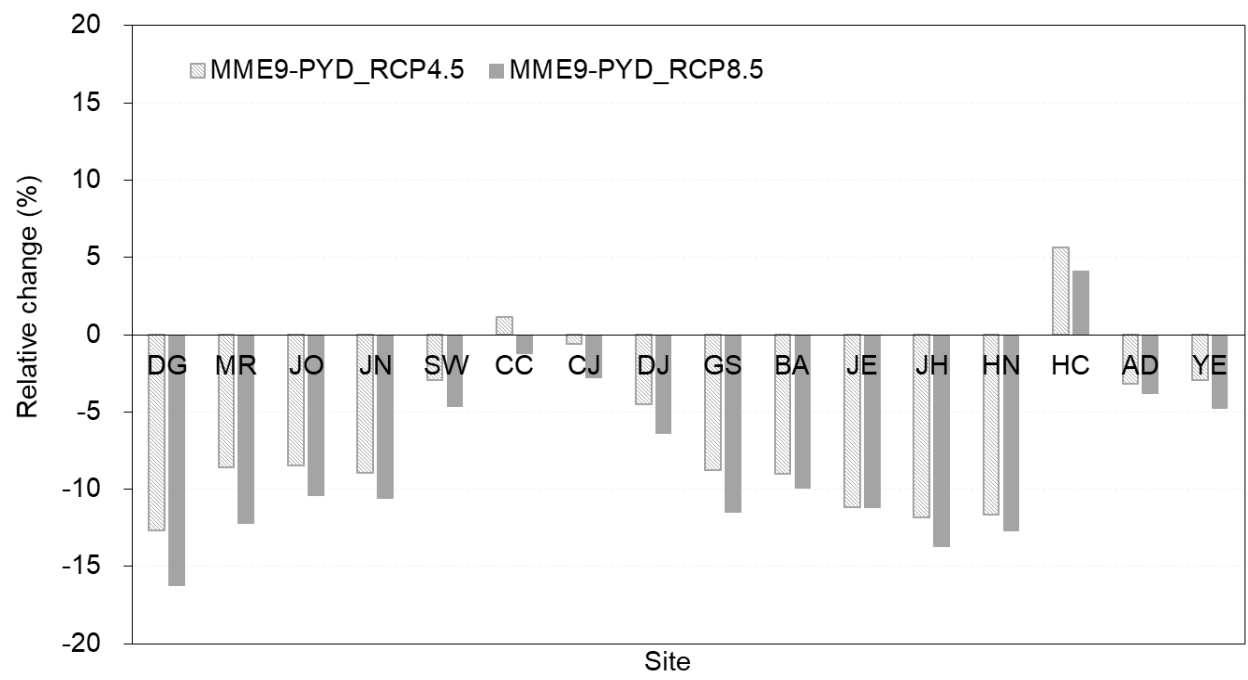

Figure 6: Relative change of the MME9-PYD of the Representative Concentration Pathways (RCP) 4.5 and 8.5 scenarios predicted for a future period (2021-2050), compared with the MME9-PYD during the historical period (1976-2005) at 16 sites (DG: Daegu, MR: Miryang, JO: Jeonju, SW: Suwaon, CC: Chuncheon, CJ: Cheungju, DJ: Daejeon, GS: Gusan, BA: Buan, JE: Jeungeup, JH: Jangheung, HN: Haenam, AD: Andong, and YE: Youngdeck). The MME9-PYD RCP4.5 and the MME9-PYD_RCP8.5 represented respectively the mean potential yields averaged from the individual SIM-PYD of nine GCMs for RCP4.5 and RCP8.5.

climate change scenarios. That is, the MME approach, according to the type and number of included Global Climate Models (GCMs) can more accurately predict the mean and reduce the estimation error (e.g., RMSE). However, the MME approach is not suitable for the estimation of the potential yield during extreme or abnormal climate events due to the large error in the annual variation of the predicted potential yield. Since climate has too many influencing factors, such as topography and regional land cover, modelling will need to find downscaling methods that can predict local climates from Regional Climate Models (RCMs) or GCMs. Research to improve results must be continuously conducted.

The relative changes in the predicted potential yields of soybeans using individual climate models varied, with the spatial averages of these relative changes for the predicted potential yield at 16 sites during the near future period (2021-2050) estimated as $-6.1 \%$ and $-8.0 \%$ for the RCP4.5 and RCP8.5 scenarios, respectively. However, these averages do not represent the whole of South Korea in terms of changes in the potential yield of soybeans under future climate change scenarios. In conclusion, based on the results of this study, it is expected that the importance of research on field crops and modeling of climate change effects will be raised in South Korea.

\section{Acknowledgement}

This study was supported by PJ011425032016 of Rural Development Administration (RDA), and conducted by the APEC Climate Center.

\section{References}

1. Gibson LR, Mullen RE (1996) Influence of day and night temperature on soybean seed yield. Crop Sci 36: 98-104.

2. Herrero MP, Johnson RR (1980) High temperature stress and pollen viability of maize. Crop Sci 20: 796-800.

3. https://agcrops.osu.edu/newsletters/2012/23

4. Lobell DB, Hammer GL, McLean G, Messina C, Roberts MJ, et al. (2013) The critical role of extreme heat for maize production in the United States. Nat Clim Change 3: 497-501.

5. KMA (2012) Climate Outlook for Korean Peninsula. Korean Meteorological Administration.
6. KMA (2015) Report of Extreme Climate in Korean Peninsula. Korean Meteorological Administration.

7. Liu B, Asseng S, Liu L, Tang L, Cao W (2016) Testing the responses of four wheat crop models to heat stress at anthesis and grain filling. Glob Chang Biol 22: 1890-1903.

8. Maiorano A, Martre P, Asseng S, Ewert F, Muller C, et al. (2017) Crop mode improvement reduces the uncertainty of the response to temperature of multimodel ensembles. Field Crops Res 202: 5-20.

9. Lee CK, Kim J, Shon J, Yang WH, Yoon YH, et al. (2012) Impacts of climate change on rice production and adaptation method in Korea as evaluated by simulation study. Korean J Agric For Meteorol 14: 207-221.

10. Hong SY, Hur J, Ahn JB, Lee JM, Min BK, et al. (2012) Estimating rice yield using MODIS NDVI and meteorological data in Korea. Korean J Remote Sens 28: $509-520$.

11. Lee KJ, Nguyen DN, Choi DH, Ban HY, Lee BW (2015) Effects of elevated air temperature on yield and yield components of rice. $\mathrm{K} \mathrm{J}$ Agric Forest Meteorol 17: $156-164$.

12. Lee KJ, Kim DJ, Ban HY, Lee BW (2015) Genotypic differences in yield and yield-related elements of rice under elevated air temperature conditions. $\mathrm{K} \mathrm{J}$ Agric Forest Meteorol 17: 306-316.

13. Lee KM, Baek HJ, Park SH, Kang HS, Cho CH (2012) Future projection of changes in extreme temperatures using high resolution regional climate change scenario in the Republic of Korea. Korean J Geogr Soc 47: 208-225.

14. Becker N, Ulbrich U, Klein R (2015) Systematic large-scale secondary circulations in a regional climate model. Geophysic Res Lett 42: 4142-4149.

15. Giorgi F, Coppola E, Solmon F, Mariotti L, Sylla MB, et al. (2012) RegCM4 model description and preliminary tests over multiple CORDEX domains. Clim Res 52: 7-29.

16. Gudmundsson L, Bremnes JB, Haugen JE, Skaugen TE (2012) Downscaling RCM precipitation to the station scale using quantile mapping-a comparison of methods. Hydrol Earth Sys Sci 16: 3383-3390.

17. Eum HI, Cannon AJ, Murdock TQ (2017) Intercomparison of multiple statistica downscaling methods: multi-criteria model selection for South Korea. Stochastic Env Res Risk Assess 31: 683-703.

18. Murphy JM, Sexton DM, Barnett DN, Jones GS (2004) Quantification of modelling uncertainties in a large ensemble of climate change simulations. Nature 430: 768-772.

19. Semenov MA, Stratonovitch $P(2010)$ Use of multi-model ensembles from global climate models for assessment of climate change impacts. Clim Res 41: 1-14. 
Citation: Chung U, Kim YU, Seo BS, Seo MC (2017) Evaluation of Variation and Uncertainty in the Potential Yield of Soybeans in South Korea Using Multi-model Ensemble Climate Change Scenarios. Agrotechnology 6: 158. doi: 10.4172/2168-9881.1000158

Page 10 of 10

20. Diffenbaugh NS, Giorgi F (2012) Climate change hotspots in the CMIP5 global climate model ensemble. Clim Change 114: 813-822.

21. The Intergovernmental Panel on Climate Change (IPCC) (2013) The physical science basis: contribution of working group I to the fifth assessment report of the intergovernmental panel on climate change. Cambridge University Press, Cambridge, United Kingdom, NY, USA.

22. The Intergovernmental Panel on Climate Change (IPCC) (2014) Climate change 2014: synthesis report. Contribution of working groups I, II and III to the fifth assessment report of the intergovernmental panel on climate change, IPCC, Geneva, Switzerland.

23. Chung U, Cho JP, Seo MC, Jung WS (2015) Evaluation of agro-climatic index in Korean Peninsular using multi-model ensemble downscaled climate prediction of CIMP5. Abstract book of International Scientific Conference, Paris, France, pp: 316-317.

24. Bassu S, Brisson N, Durand JL, Boote K, Lizaso J, et al. (2014) How do various maize crop models vary in their responses to climate change factors? Glob Change Biol 20: 2301-2320.

25. Martre P, Wallach D, Asseng S, Ewert F, Jones JW, et al. (2015) Multimode ensembles of wheat growth: many models are better than one. Glob Chang Biol 21: 911-925.

26. McDermid SP (2015) The AgMIP coordinated climate crop modeling project (C3MP): methods and protocols. Handbook of Climate Change and Agroecosystems: The Agricultural Model Intercomparison and Improvement Project (AgMIP). Imperial College Press, London.

27. Di Paola A, Valentini R, Santini M (2016) An overview of available crop growth and yield models for studies and assessments in agriculture. J Sci Food Agric 96: 709-714.

28. Boote KJ, Jone JW, Hoogenboom G, Wilkerson GG, Jagtap SSS (1989) PNUTGRO V1.02: Peanut crop growth simulation model. User's Guide. Florida Agricultural Experiment Station Journal No. 8420. University of Florida Gainesville, FL, USA p: 76.
29. Jones JW, Hoogenboom G, Porter CH, Boote K, Batchelor WD, et al. (2003) The DSSAT cropping system model. Eur J Agron 18: 235-265.

30. Hoogenboom G, Jones JW, Wilkens PW, Porter CH, Boote KJ, et al. (2010) Decision Support System for Agrotechnology Transfer (DSSAT) Version 4.5 [CDROM]. University of Hawaii, Honolulu.

31. Kim SD, Hong EH, Lee YH, Moon YH, Kim HS, et al. (1992) Resistant to disease good in seed quality, high yielding and widely adapted new soybean variety" Taekwangkong“. Research Reports of the Rural Development Administration (Korea Republic).

32. Kim SK, Park JS, Lee ES, Jang JH, Chung U, et al. (2004) Development and use of digital climate models in Northern Gyunggi province-I. Derivation of DCMs from historical climate data and local land surface features. Korean $J$ Agric For Meteorol 6: 49-60.

33. Kim DJ, Kim SO, Moon KH, Yun JI (2012) An outlook on cereal grains production in South Korea based on crop growth simulation under the RCP8. 5 climate change scenarios. Korean J Agric For Meteorol 14: 132-141.

34. Park HJ, Han WY, Oh KW, Kim HT, Shin SO, et al. (2014) Growth and yield components responses to delayed planting of soybean in southern region of Korea. Korean J Crop Sci 59: 483-491.

35. Lee D, Min SK, Jin J, Lee JW, Cha DH, et al. (2017) Thermodynamic and dynamic contributions to future changes in summer precipitation over Northeast Asia and Korea: a multi-RCM study. Clim Dyn 1-19.

36. Chung U, Cho HS, Kim JH, Sang WG, Shin P, et al. (2016) Responses of soybean yield to high temperature stress during growing season: A case study of the Korean soybean. Korean J Agric For Meteorol 18:188-198.

37. Chung U, Kim JH, Kim KH (2016) Variation and uncertainty in the predicted flowering dates of cherry blossoms using the CMIP5 climate change scenario. Asia-Pacific J Atmos Sci 52: 509-518. 